\title{
Segregation of Dopants at WC/Co and WC/WC Interfaces in Solid-State-Sintered WC-VC-Cr${ }_{3} \mathrm{C}_{2}$-Co Cemented Carbides
}

\author{
Masaru Kawakami* and Kozo Kitamura
}

Fuji Die Co. Ltd., 36-1, Hadano 257-0015, Japan

The segregation of $\mathrm{V}$ and $\mathrm{Cr}$ at $\mathrm{WC} / \mathrm{Co}$ and $\mathrm{WC} / \mathrm{WC}$ interfaces in ultrafine-grained WC-0.7VC-1.4Cr $\mathrm{C}_{2}-10 \mathrm{Co}\left(\mathrm{mass}_{2} \%\right.$ ) cemented carbides produced through solid-state sintering and semi-sintering was investigated. This segregation was compared against that of a liquid-statesintered specimen to elucidate the mechanism by which WC grain growth is inhibited by $\mathrm{V}$ and $\mathrm{Cr}$. The $\mathrm{V}$ and $\mathrm{Cr}$ were found to segregate at the $\mathrm{WC} / \mathrm{Co}$ and WC/WC interfaces during solid-state sintering and semi-sintering, but no differences were observed in the $\mathrm{V}$ and $\mathrm{Cr}$ concentrations at the interfaces among the liquid-state-sintered, solid-state-sintered and semi-sintered specimens. Furthermore, these concentrations were unchanged by quenching of the solid-state-sintered specimen. From these results, it was concluded that $(\mathrm{V}, \mathrm{W}, \mathrm{Cr}) \mathrm{C}_{x}$ segregation layers are stably formed at the WC/Co and WC/WC interfaces at a temperature below the solidus of the Co phase, but almost dissolve in the liquid Co phase once the temperature exceeds its liquidus. Thus, the $(\mathrm{V}, \mathrm{W}, \mathrm{Cr}) \mathrm{C}_{x}$ segregation layers observed at the $\mathrm{WC} / \mathrm{Co}$ and $\mathrm{WC} / \mathrm{WC}$ interfaces at room temperature are formed during the cooling that follows the liquid-state sintering. This supports the finding that WC grain growth is inhibited by the adsorption of dopant atoms onto steps/kinks on the WC surface during liquid-state sintering, as well as by the segregation layers formed on the WC surface during solid-state sintering. [doi:10.2320/matertrans.M2015198]

(Received May 25, 2015; Accepted August 19, 2015; Published October 2, 2015)

Keywords: ultrafine-grained cemented carbide, segregation layer, solid-state sintering, semi-sintering, phase equilibrium

\section{Introduction}

Submicron- and ultrafine-grained WC-Co-based cemented carbides are being used more frequently in micro-punches and sharp blades, as these have the advantages of superior hardness and higher compressive and edge strengths than medium-grained cemented carbides. These submicron- and ultrafine-grained cemented carbides are typically produced via liquid-state sintering using dispersed grains of WC powder less than $1 \mu \mathrm{m}$ in size, in combination with Co powder as a binder phase and grain-growth inhibitors such as $\mathrm{VC}, \mathrm{Cr}_{3} \mathrm{C}_{2}$, TaC or TiC powder. ${ }^{1-3)}$ To ensure the stable production of cemented carbides with good mechanical properties, it is important to fully understand the WC graingrowth inhibition mechanism caused by the dopants during liquid-state sintering. This is because the appropriate amount of grain-growth inhibitor is dependent on the inhibition mechanism.

Lay et al. have reported that grain growth in $\mathrm{VC}$-doped WC-Co cemented carbides is inhibited by thin $(\mathrm{V}, \mathrm{W}) \mathrm{C}_{x}$ layers on the $\mathrm{WC}(0001)$ surface, which act as barriers to the precipitation of $\mathrm{W}$ onto the surface from the liquid $\mathrm{Co}$ phase. ${ }^{4)}$ This is based on investigations of VC-doped WC-Co cemented carbides using high-resolution transmission microscopy (HRTEM) and energy dispersive X-ray spectroscopy (EDS), which have revealed segregation layers at the WC/Co interface that exhibit good matching between the $(0001)_{\mathrm{WC}}$ and $(111)_{\mathrm{VC}}$ lattice parameters. The presence of $(\mathrm{V}, \mathrm{W}) \mathrm{C}_{x}$ platelets within the $\mathrm{WC}$ grains and at stepped interfaces has also been identified. Based on investigation of an oil-quenched specimen, Sugiyama et al. have also reported that the $(\mathrm{V}, \mathrm{W}) \mathrm{C}_{x}$ layer inhibits $\mathrm{WC}$ grain growth. ${ }^{5)}$ On the other hand, Hayashi previously suggested (i.e., prior to studies ${ }^{4,5)}$ ) that WC grain growth is inhibited by the adsorption-desorption of dopants such as V, Cr, Ta and Ti at

*Corresponding author, E-mail: kawakami.2008@fujidie.co.jp steps/kinks during sintering. ${ }^{6)}$ This was based on the premise that the solubility limit of dopants in the WC phase is fairly_low, and suggests that there is no segregation layer formed during liquid state sintering. It has been verified that the extent of segregation concentration at the $\mathrm{WC} / \mathrm{Co}$ and $\mathrm{WC} / \mathrm{WC}$ interfaces is reduced by an increase in the cooling rate following sintering, ${ }^{7)}$ and although the grain growth rate is independent of the WC crystal orientation during liquidstate sintering, the degree of segregation at the interface is nevertheless dependent on the WC crystal orientation. ${ }^{7)}$ Furthermore, the inhibition of grain growth by $\mathrm{TaC}$ addition in TaC-doped WC-Co cemented carbide is greater than that seen with $\mathrm{TiC}$ addition, despite their being no visible segregation layer on the $\mathrm{WC}(0001)$ surface. ${ }^{8)}$ Based on these results, it would seem that the segregation layer of graingrowth inhibitors at the $\mathrm{WC} / \mathrm{Co}$ interface cannot be present at the liquid-state-sintering temperature, but rather is formed during the cooling stage that follows sintering. Thus, the most important factor in determining the grain-growth inhibition mechanism during liquid-state sintering of submicron- and ultrafine-grained cemented carbide is knowing precisely when the grain-growth inhibitors segregate at the $\mathrm{WC} / \mathrm{Co}$ and $\mathrm{WC} / \mathrm{WC}$ interfaces.

If we consider the solubility of $\mathrm{V}$ in the $\mathrm{Co}-\mathrm{W}-\mathrm{V}-\mathrm{C}$ phase (i.e., the liquid and solid Co phases) of a WC-VC-Co cemented carbide based on a pseudo-binary VC-Co phase diagram, ${ }^{9)}$ then it is apparent that the amount of $\mathrm{V}$ added in a previous work $^{7)}$ was less than the solubility limit of $\mathrm{V}$ in the liquid Co phase, but greater than that in the solid Co phase. Given this difference in solubility limits, it is only natural to assume that $(\mathrm{V}, \mathrm{W}) \mathrm{C}_{x}$ segregates on the $\mathrm{WC}$ surface during cooling. However, if $(\mathrm{V}, \mathrm{W}) \mathrm{C}_{x}$ segregates on the $\mathrm{WC}$ surface during sintering at temperatures below the Co solidus, then this would suggest not only that the $(\mathrm{V}, \mathrm{W}) \mathrm{C}_{x}$ layer exists stably at solid-state-sintering temperatures, but also that the $\mathrm{V}$ atoms have sufficient diffusion force to form a layer in the solid phase. The possibility also exists that the grain growth 
inhibition mechanism may differ between liquid-state and solid-state sintering. Therefore, this study investigates the microstructures and chemical concentrations at the $\mathrm{WC} / \mathrm{Co}$ and $\mathrm{WC} / \mathrm{WC}$ interfaces in ultrafine-grained $\mathrm{WC}-\mathrm{VC}-\mathrm{Cr}_{3} \mathrm{C}_{2}-$ Co cemented carbides produced using liquid-state sintering, solid-state sintering and semi-sintering. The grain-growthinhibitor segregation mechanism is also herein discussed by relating it to the phase equilibrium.

\section{Experimental Procedure}

A mixed powder of $\mathrm{WC}+0.7 \mathrm{VC}+1.4 \mathrm{Cr}_{3} \mathrm{C}_{2}+10 \mathrm{Co}$ (mass $\%)$ was prepared by ball-milling commercially available powders of WC (average particle size: $0.07 \mu \mathrm{m}$, produced by A.L.M.T. Corp., Japan), VC $(0.8 \mu \mathrm{m}$, same producer as above), $\mathrm{Cr}_{3} \mathrm{C}_{2}(1.5 \mu \mathrm{m}$, same producer as above $)$ and Co $(0.7 \mu \mathrm{m}$, produced by Umicore, Belgium). The carbon content was adjusted so that the value after sintering would be the middle value in the $\mathrm{WC}+\mathrm{Co}$ two-phase region. This mixed powder was then uniaxially pressed at $1500 \mathrm{MPa}$ to form green compacts with dimensions of $5 \mathrm{~mm} \times 10 \mathrm{~mm} \times 30 \mathrm{~mm}$. These green compacts were sintered at 1273,1473 and $1593 \mathrm{~K}$ for $3.6 \mathrm{ks}$ under vacuum for semi-sintering, solid-state sintering and liquid-state sintering, respectively, and then cooled at a rate of $0.067 \mathrm{~K} / \mathrm{s}$. The temperatures of 1273 and $1473 \mathrm{~K}$ were chosen so as to be below the solidus of the Co phase (or more specifically, the $\mathrm{Co}-\mathrm{W}-\mathrm{V}-\mathrm{Cr}-\mathrm{C}$ solution), whereas the temperature of $1593 \mathrm{~K}$ was selected on the basis that it was above the liquidus of the Co phase. Specimens of $\mathrm{WC}-0.7$ mass $\% \mathrm{VC}-$ 1.4 mass $\% \mathrm{Cr}_{3} \mathrm{C}_{2}-10$ mass $\% \mathrm{Co} \quad(\mathrm{W}-0.9$ at $\% \mathrm{~V}-0.7$ at $\% \mathrm{Cr}-36.6$ at $\% \mathrm{C}-26.6$ at $\% \mathrm{Co}$ ) without any discernible third phases, similar to carbon-deficient $\mathrm{M}_{6} \mathrm{C}$-type complex carbides or graphite, were obtained. For comparative purposes, a quenched specimen was also prepared using a specimen sintered at $1473 \mathrm{~K}$, which was achieved by reheating at $1473 \mathrm{~K}$ for $1.8 \mathrm{ks}$, followed by quenching in icy water. The quenching rate was estimated to be approximately $50 \mathrm{~K} / \mathrm{s}$ based on the color variation of the specimen during the process.

Each of the four specimen types was fractured into two samples using a three-point bending method. One sample was used for scanning electron microscopy (SEM) analysis using an S-4800-type field emission scanning electron microscope (FE-SEM; Hitachi High-Technologies Corporation), while the other was used for HRTEM observation with a HF-2000type field emission transmission electron microscope (FETEM; Hitachi High-Technologies Corporation) operating at an acceleration voltage of $200 \mathrm{kV}$. The fracture surfaces of the specimens used for SEM observation, excluding that sintered at $1273 \mathrm{~K}$, were etched using dilute hydrochloric acid to remove the Co binder phase and allow the WC grains to be observed more clearly. The specimens for HRTEM observation were cut to a size of $1 \mathrm{~mm} \times 2 \mathrm{~mm} \times 2 \mathrm{~mm}$ using a diamond blade cutter, polished to a thickness of $10 \mu \mathrm{m}$ using a diamond wheel, and finally thinned to $30-70 \mathrm{~nm}$ using an Ar-ion milling apparatus. The micro-region concentration of elements at the $\mathrm{WC} / \mathrm{Co}$ and $\mathrm{WC} / \mathrm{WC}$ interfaces was examined using a SIGMA-type EDS (Kevex Co. Ltd) with an effective analysis diameter of $3 \mathrm{~nm}$. These concentrations were scaled to a total of $100 \%$ for the W, V, Cr and Co concentrations because of a lack of quantitative analysis of $\mathrm{C}$ by EDS.

\section{Results}

Figure 1 shows SEM micrographs of the mixed powder (a) and the fracture surfaces of specimens sintered at 1273 (b), 1473 (c) and $1593 \mathrm{~K}$ (d). It was noted that the specimen semisintered at $1273 \mathrm{~K}$ did not shrink because of the overly low temperature used, whereas almost fully densified sintered compacts were obtained by solid-state sintering at $1473 \mathrm{~K}$ and liquid-state sintering at $1593 \mathrm{~K}$. The rounded $\mathrm{WC}$ grains of the semi-sintered specimen shown in Fig. 1(b) also reveal no evidence of grain growth from the mixed powder in Fig. 1(a). At the higher temperature of solid-state sintering (Fig. 1(c)), angular grains were formed as a result of intensified atom migration, but the grain size remained almost identical to that of the semi-sintered specimen. In the case of the specimen produced by liquid-state sintering (Fig. 1(d)), columnar triangle-shaped WC grains were observed to be scattered throughout the microstructure, with the WC grain size increased a little by the dissolutionreprecipitation of WC during liquid-state sintering. The grain growth rate is considered independent of the WC crystal orientation, because grains with a high aspect ratio that would indicate a difference in rate were not found in the microstructure.

In the HRTEM micrograph of the liquid-state-sintered specimen shown in Fig. 2, the dark to light gray quadrangular regions are $\mathrm{WC}$ grains, whereas the other light gray region surrounding the WC grains is the Co phase. The right facet of the large WC grain at the center of the micrograph was determined to be the $\mathrm{WC}(0001)$ basal plane from the electron diffraction pattern. An enlarged micrograph of the interface between this $\mathrm{WC}(0001)$ basal plane and the Co phase (hereafter referred to as $\mathrm{WC}_{\mathrm{B}} / \mathrm{Co}$ ), indicated by arrow (a) in Fig. 2, is shown in Fig. 3, in which a layer of approximately $1 \mathrm{~nm}$ in thickness can be seen. The variation in the concentrations of $\mathrm{V}$ and $\mathrm{Cr}$ in the vicinity of this $\mathrm{WC}_{\mathrm{B}} / \mathrm{Co}$ interface was therefore analyzed, as shown in Fig. 4, this revealed that the interface layer is enriched in $\mathrm{V}$ and $\mathrm{Cr}$. The concentrations of the elements at the $W C(1010)$ columnar plane/Co $\left(\mathrm{WC}_{\mathrm{C}} / \mathrm{Co}\right)$ interface and the $W C(10 \overline{10})$ columnar plane/WC randomly oriented plane $\left(\mathrm{WC}_{\mathrm{C}} / \mathrm{WC}_{\mathrm{R}}\right)$ interface, indicated by arrows (b) and (c) in Fig. 2, were also analyzed, the results of which are shown in Table 1. No data was obtained for the $\mathrm{WC}(0001)$ basal plane/WC randomly oriented plane $\left(\mathrm{WC}_{\mathrm{B}} / \mathrm{WC}_{\mathrm{R}}\right)$ interface. It is evident from this that the $\mathrm{V}$ concentration at the interface is dependent on the WC crystal orientation, as was the case with a WC-VC-Co cemented carbide examined in a previous work. ${ }^{7)}$ On the other hand, the $\mathrm{Cr}$ concentration at the interface is clearly independent of the $\mathrm{WC}$ crystal orientation. It was also confirmed that $\mathrm{V}, \mathrm{Cr}$ and $\mathrm{Co}$ are segregated at the $\mathrm{WC}_{\mathrm{C}} / \mathrm{WC}_{\mathrm{R}}$ interface.

In the HRTEM micrograph of the specimen produced by solid-state sintering at $1473 \mathrm{~K}$ shown in Fig. 5, the presence of stacking faults within the WC grains (the stripe pattern at the lower left of the micrograph) demonstrate that the 

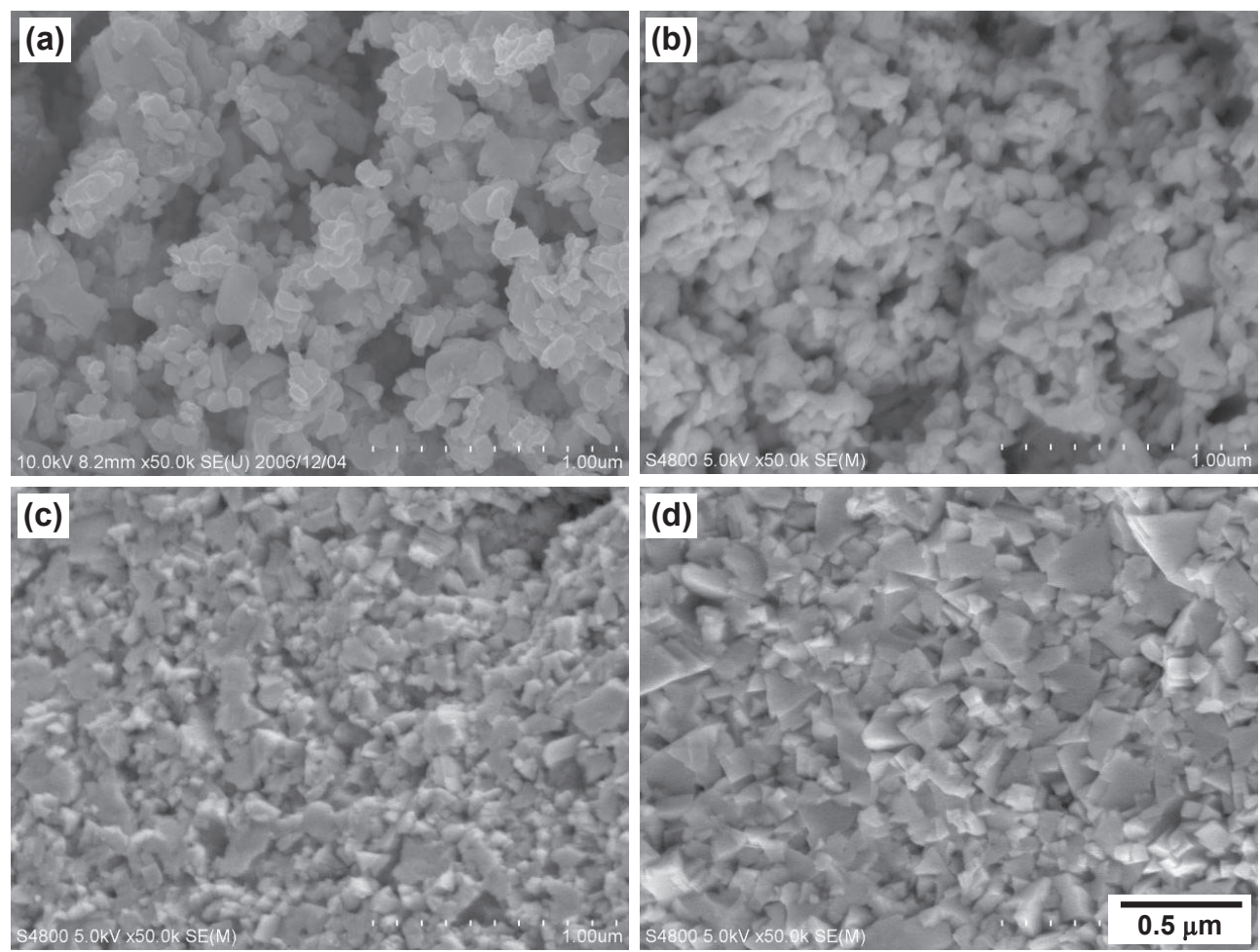

Fig. 1 SEM micrographs of (a) mixed powder and fracture surfaces of WC- $0.7 \mathrm{VC}-1.4 \mathrm{Cr}_{3} \mathrm{C}_{2}-10 \mathrm{Co}$ cemented carbides sintered at (b) 1273 , (c) 1473 and (d) $1593 \mathrm{~K}$. The fracture surfaces of the specimens sintered at 1473 and $1593 \mathrm{~K}$ were etched using dilute hydrochloric acid to remove the Co phase surrounding the $\mathrm{WC}$ grain.

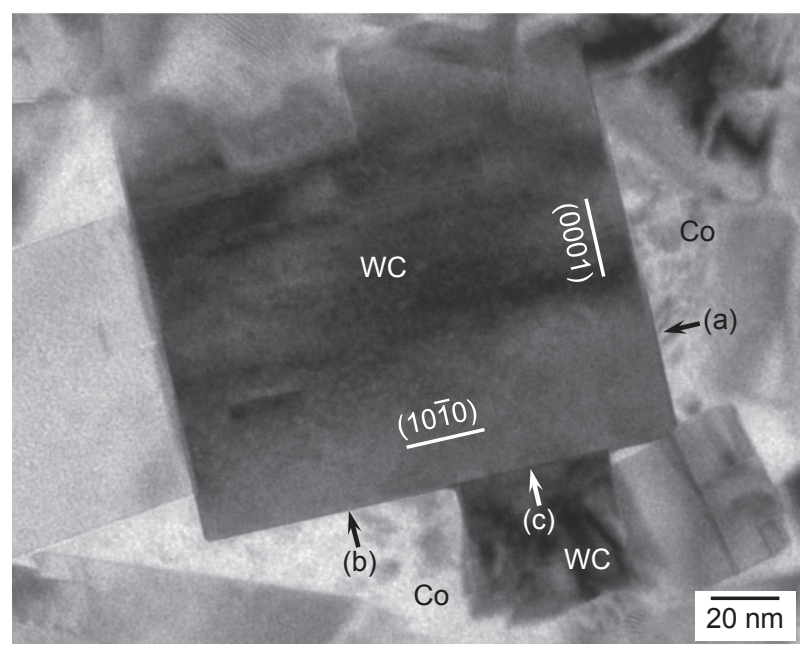

Fig. 2 HRTEM micrograph of a liquid-state-sintered specimen at $1593 \mathrm{~K}$. Arrows (a), (b) and (c) indicate the concentration analysis points listed in Table 1.

rearrangement of WC atoms was not significant. An enlarged micrograph taken in the vicinity of arrow (d) is shown in Fig. 6, in which a layer as pronounced as that seen in the liquid-state-sintered specimen can be observed at the $\mathrm{WC}_{\mathrm{B}}$ / $\mathrm{Co}$ and $\mathrm{WC}_{\mathrm{B}} / \mathrm{WC}_{\mathrm{R}}$ interfaces. The concentration of elements at the $\mathrm{WC}_{\mathrm{B}} / \mathrm{Co}, \mathrm{WC}_{\mathrm{B}} / \mathrm{WC}_{\mathrm{R}}$ and $\mathrm{WC}_{\mathrm{C}} / \mathrm{WC}_{\mathrm{R}}$ interfaces, as indicated by arrows (e), (d) and (g) in Fig. 5, are listed in Table 2. The EDS result for the $\mathrm{WC}_{\mathrm{C}} / \mathrm{Co}$ interface (Column (f), Table 2) was obtained from another grain in the same specimen. With the solid-state-sintered specimen, it was found that $\mathrm{V}$ and $\mathrm{Cr}$ were segregated at all interfaces, while

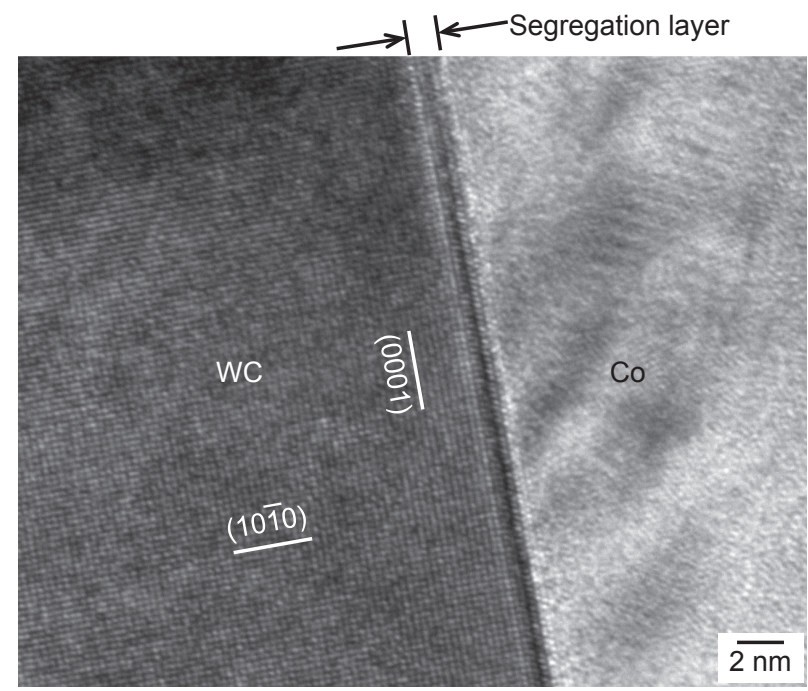

Fig. 3 HRTEM micrograph of $\mathrm{WC}_{\mathrm{B}} / \mathrm{Co}$ interface in the liquid-statesintered specimen. This is a magnification of the region indicated by arrow (a) in Fig. 2.

Co segregation was confirmed only at the $\mathrm{WC}_{\mathrm{B}} / \mathrm{WC}_{\mathrm{R}}$ and $\mathrm{WC}_{\mathrm{C}} / \mathrm{WC}_{\mathrm{R}}$ interfaces. The $\mathrm{V}$ and $\mathrm{Cr}$ concentrations at the interface of solid-state-sintered specimen were identical to those of the liquid-state-sintered specimen.

Figure 7 shows a HRTEM micrograph of the specimen that was semi-sintered at $1273 \mathrm{~K}$, in which rounded rectangle-shaped agglomerates of WC grains can be observed. The crystal orientation of the WC grains was determined from the electron diffraction pattern, but the orientation of the uppermost WC grain next to the agglomerates remains unknown. Layers were observed at 


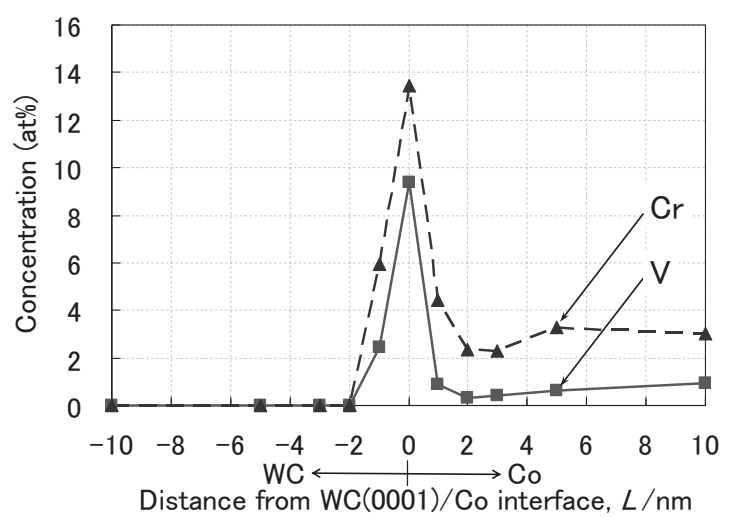

Fig. 4 Variation in $\mathrm{V}$ and $\mathrm{Cr}$ concentration as a function of distance from the WC(0001)/Co interface shown in Fig. 2.

Table 1 Concentration of elements (at $\%$ ) at $\mathrm{WC}_{\mathrm{B}} / \mathrm{Co}, \mathrm{WC}_{\mathrm{C}} / \mathrm{Co}$ and $\mathrm{WC}_{\mathrm{C}} /$ $\mathrm{WC}_{\mathrm{R}}$ interfaces in WC-0.7VC-1.4C $\mathrm{Cr}_{3} \mathrm{C}_{2}-10 \mathrm{Co}(\mathrm{W}-0.9$ at $\% \mathrm{~V}-0.7$ at $\% \mathrm{Cr}-$ 36.6 at\% $\%-26.6$ at $\% \mathrm{Co}$ ) cemented carbide produced by liquid-state sintering at $1593 \mathrm{~K}$ for $3.6 \mathrm{ks}$. The analysis point is indicated in Fig. 2.

\begin{tabular}{ccccc}
\hline & (a) & & (b) & (c) \\
\cline { 2 - 5 } & $\mathrm{WC}_{\mathrm{B}} / \mathrm{Co}$ & $\mathrm{WC}_{\mathrm{B}} / \mathrm{WC}_{\mathrm{R}}$ & $\mathrm{WC}_{\mathrm{C}} / \mathrm{Co}$ & $\mathrm{WC}_{\mathrm{C}} / \mathrm{WC}_{\mathrm{R}}$ \\
\hline $\mathrm{V}$ & 9 & - & 2 & 4 \\
$\mathrm{Cr}$ & 15 & - & 16 & 15 \\
$\mathrm{Co}$ & 52 & - & 52 & 13 \\
$\mathrm{~W}$ & 24 & - & 30 & 68 \\
\hline
\end{tabular}

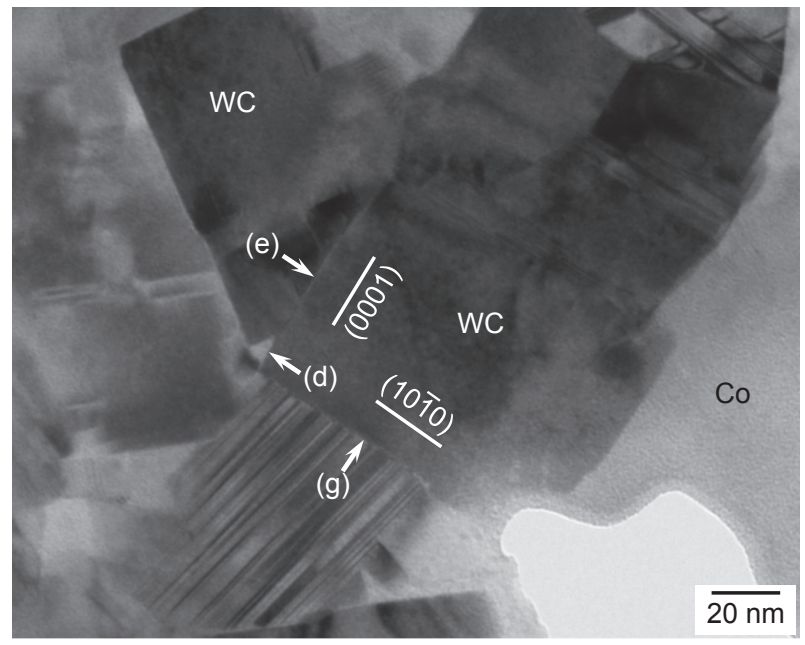

Fig. 5 HRTEM micrograph of a specimen solid-state-sintered at $1473 \mathrm{~K}$. Arrows (d), (e) and (g) indicate the EDS analysis points listed in Table 2.

the $\mathrm{WC}_{\mathrm{B}} / \mathrm{WC}_{\mathrm{B}}$ and $\mathrm{WC}_{\mathrm{B}} / \mathrm{WC}_{\mathrm{R}}$ interfaces, as shown in Fig. 8, with the concentration of elements at the $\mathrm{WC}_{\mathrm{B}} / \mathrm{Co}$, $\mathrm{WC}_{\mathrm{B}} / \mathrm{WC}_{\mathrm{R}}$ and $\mathrm{WC}_{\mathrm{C}} / \mathrm{Co}$ and $\mathrm{WC}_{\mathrm{C}} / \mathrm{WC}_{\mathrm{C}}$ interfaces (the interfaces are indicated by arrows (h), (i), (j) and (k), respectively) given in Table 3 . Hence, it was found that both $\mathrm{V}$ and $\mathrm{Cr}$ segregated at the $\mathrm{WC}_{\mathrm{B}} / \mathrm{Co}, \mathrm{WC}_{\mathrm{B}} / \mathrm{WC}_{\mathrm{R}}, \mathrm{WC}_{\mathrm{C}} / \mathrm{Co}$ and $\mathrm{WC}_{\mathrm{C}} / \mathrm{WC}_{\mathrm{R}}$ interfaces, whereas $\mathrm{Co}$ segregated at the $\mathrm{WC}_{\mathrm{B}} / \mathrm{WC}_{\mathrm{R}}$ and $\mathrm{WC}_{\mathrm{C}} / \mathrm{WC}_{\mathrm{R}}$ interfaces.

\section{Discussion}

Segregation of $\mathrm{V}$ and $\mathrm{Cr}$ was observed at the $\mathrm{WC} / \mathrm{Co}$ and

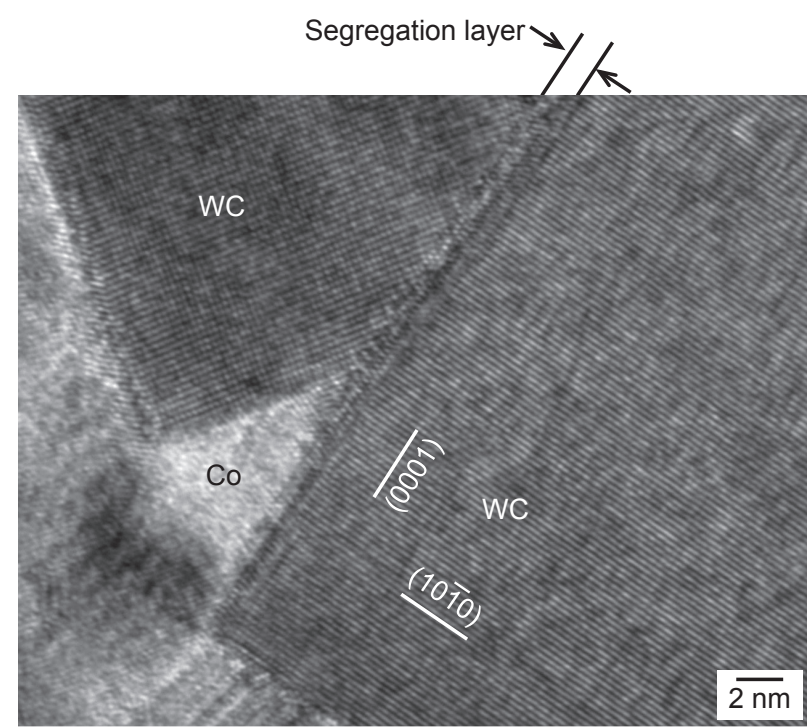

Fig. 6 HRTEM micrograph showing the $\mathrm{WC}_{\mathrm{B}} / \mathrm{Co}$ interface of a specimen solid-state-sintered at $1473 \mathrm{~K}$. This is a magnification of the region indicated by arrow (d) in Fig. 5 .

Table 2 Concentration of elements (at $\%$ ) at $\mathrm{WC}_{\mathrm{B}} / \mathrm{Co}, \mathrm{WC}_{\mathrm{C}} / \mathrm{Co}$ and $\mathrm{WC}_{\mathrm{C}} /$ $\mathrm{WC}_{\mathrm{R}}$ interfaces in WC-0.7VC-1.4 $\mathrm{Cr}_{3} \mathrm{C}_{2}-10 \mathrm{Co}$ (W- 0.9 at $\% \mathrm{~V}-0.7$ at $\% \mathrm{Cr}-$ 36.6 at $\% \mathrm{C}-26.6$ at $\% \mathrm{Co}$ ) cemented carbide produced by solid-state sintering at $1473 \mathrm{~K}$ for $3.6 \mathrm{ks}$. The analysis results (d), (e) and (g) were obtained from the corresponding analysis points shown in Fig. 5. The EDS result (f) was obtained from another grain within the same specimen.

\begin{tabular}{ccccc}
\hline & $(\mathrm{d})$ & $(\mathrm{e})$ & $(\mathrm{f})$ & $(\mathrm{g})$ \\
\cline { 2 - 5 } & $\mathrm{WC}_{\mathrm{B}} / \mathrm{Co}$ & $\mathrm{WC}_{\mathrm{B}} / \mathrm{WC}_{\mathrm{R}}$ & $\mathrm{WC}_{\mathrm{C}} / \mathrm{Co}$ & $\mathrm{WC}_{\mathrm{C}} / \mathrm{WC}_{\mathrm{R}}$ \\
\hline $\mathrm{V}$ & 9 & 11 & 4 & 3 \\
$\mathrm{Cr}$ & 11 & 23 & 18 & 18 \\
$\mathrm{Co}$ & 36 & 10 & 40 & 14 \\
$\mathrm{~W}$ & 44 & 56 & 38 & 65 \\
\hline
\end{tabular}

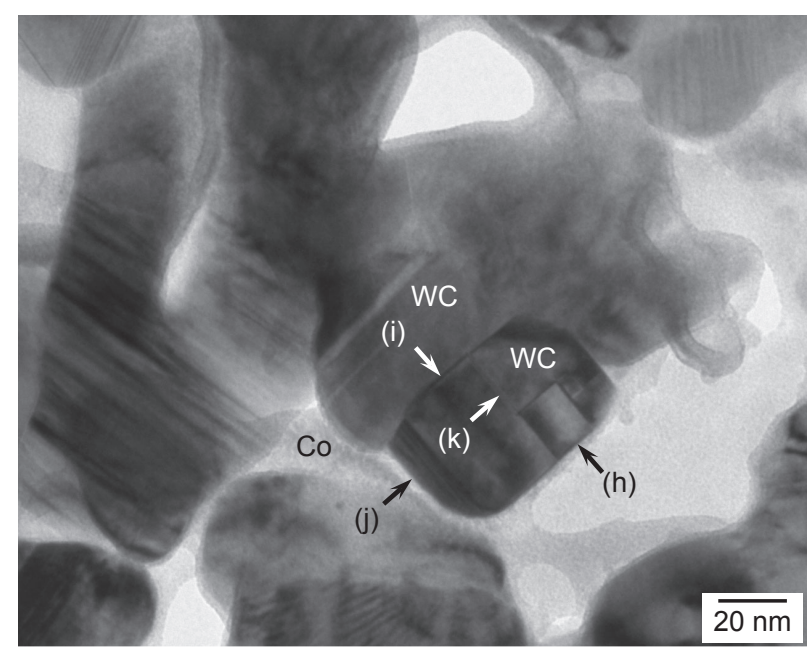

Fig. 7 HRTEM micrograph of a specimen semi-sintered at $1273 \mathrm{~K}$. Arrows (h), (i), (j) and (k) indicate the EDS analysis points listed in Table 3.

WC/WC interfaces of all specimens examined in this study which, based on reports by Lay et al., ${ }^{10)}$ suggests that the segregated phase is most likely $(\mathrm{V}, \mathrm{W}, \mathrm{Cr}) \mathrm{C}$. We believe that the segregation layer does not exist above the liquidus 


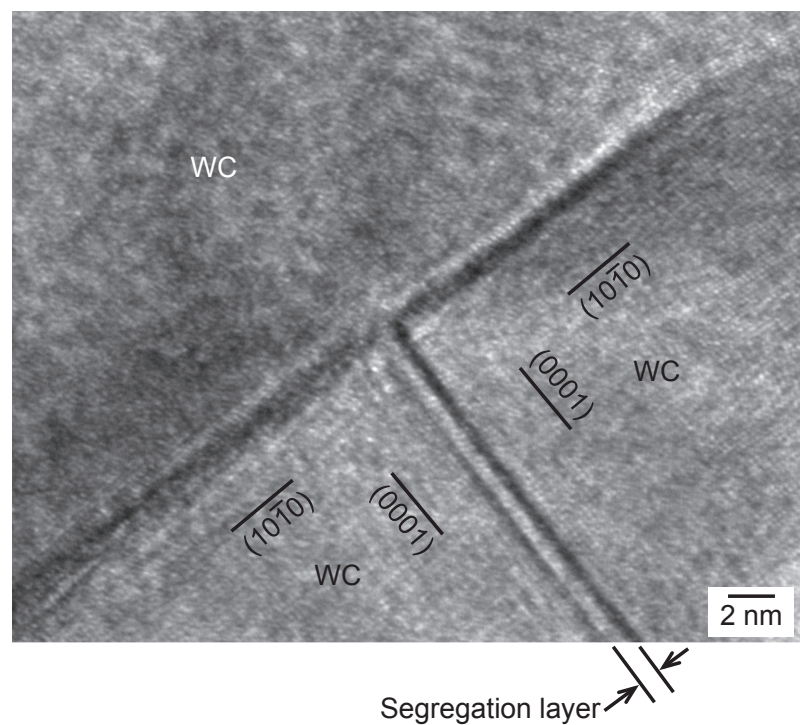

Fig. 8 HRTEM micrograph of WC/WC interfaces in the vicinity of the $\mathrm{WC} / \mathrm{WC} / \mathrm{WC}$ triple point (the intersection point between the interfaces indicated by arrows (i) and (k)) in a specimen semi-sintered at $1273 \mathrm{~K}$.

Table 3 Concentrations of elements (at $\%$ ) at $\mathrm{WC}_{\mathrm{B}} / \mathrm{Co}, \mathrm{WC}_{\mathrm{B}} / \mathrm{WC}_{\mathrm{R}}, \mathrm{WC}_{\mathrm{C}}$ $\mathrm{Co}$ and $\mathrm{WC}_{\mathrm{C}} / \mathrm{WC}_{\mathrm{R}}$ interfaces in WC-0.7VC-1.4Cr $\mathrm{C}_{2}-10 \mathrm{Co}(\mathrm{W}-0.9$ at $\% \mathrm{~V}-0.7$ at $\% \mathrm{Cr}-36.6$ at $\% \mathrm{C}-26.6$ at $\% \mathrm{Co}$ ) cemented carbide produced by semi-sintering at $1273 \mathrm{~K}$ for $3.6 \mathrm{ks}$. The analysis results (h), (i), (j) and (k) were obtained at the corresponding analysis points shown in Fig. 7.

\begin{tabular}{ccccc}
\hline & $(\mathrm{h})$ & $(\mathrm{i})$ & $(\mathrm{j})$ & $(\mathrm{k})$ \\
\cline { 2 - 5 } & $\mathrm{WC}_{\mathrm{B}} / \mathrm{Co}$ & $\mathrm{WC}_{\mathrm{B}} / \mathrm{WC}_{\mathrm{R}}$ & $\mathrm{WC}_{\mathrm{C}} / \mathrm{Co}$ & $\mathrm{WC}_{\mathrm{C}} / \mathrm{WC}_{\mathrm{R}}$ \\
\hline $\mathrm{V}$ & 12 & 6 & 5 & 6 \\
$\mathrm{Cr}$ & 9 & 13 & 13 & 8 \\
$\mathrm{Co}$ & 19 & 14 & 15 & 8 \\
$\mathrm{~W}$ & 60 & 67 & 67 & 78 \\
\hline
\end{tabular}

temperature, but rather crystallizes during cooling after sintering because of the difference in the solubility limits of $\mathrm{V}$ and $\mathrm{Cr}$ in the liquid and solid Co phases. It is this association between the sintering temperature and phase diagram that is discussed below.

The liquidus temperature of undoped WC-Co cemented carbide in the $\mathrm{WC}+$ Co two-phase region is $1630 \mathrm{~K}$ for a low carbon content (L.C.), or $1571 \mathrm{~K}$ for a high carbon content (H.C.). This is based on the pseudobinary WC-Co phase diagram shown in Fig. 9, which was modified from that given in Ref. 11). However, the actual Co liquidus temperature of the specimen decreases from that given in Fig. 9 with increasing $\mathrm{V}, \mathrm{Cr}$ and $\mathrm{C}$. For example, Hashiya et al. have reported that the temperature at which the solidification of $\mathrm{WC}-1.7 \mathrm{VC}-1.7 \mathrm{Cr}_{3} \mathrm{C}_{2}-31 \mathrm{Co}$ (mass\%) begins is 1591 and $1522 \mathrm{~K}$ for L.C. and H.C., respectively. ${ }^{12)}$ Since the carbon content of the specimens used in this study coincided with the middle value of the two-phase region, a sintering temperature of $1593 \mathrm{~K}$ was considered sufficiently high relative to the liquidus temperature of the Co phase. Also, as the added amounts of $\mathrm{V}$ and $\mathrm{Cr}$ were both below the solubility limit of these elements in liquid $\mathrm{Co}$, the specimen consisted of solid WC grains and a liquid Co phase

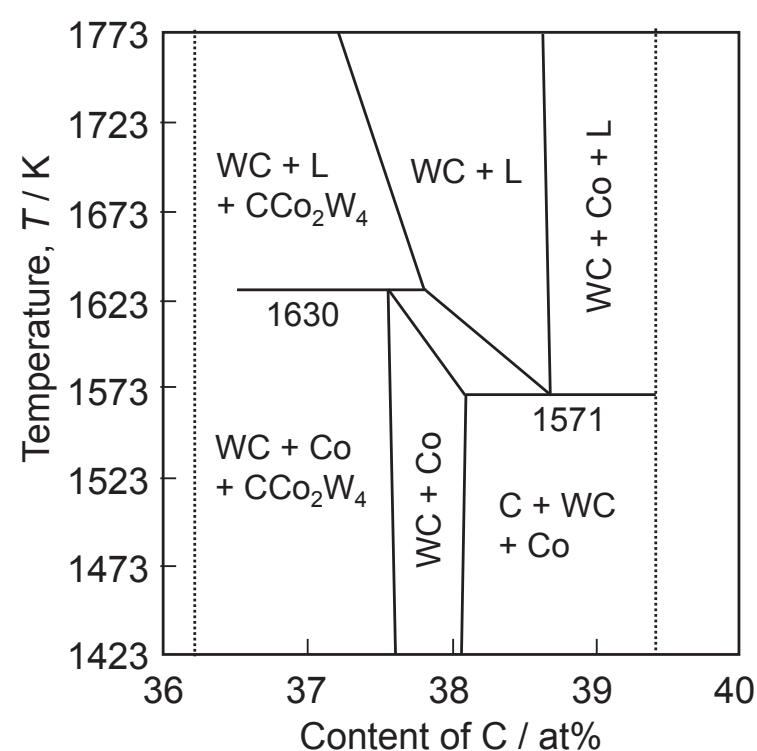

Fig. 9 Vertical section of the C-Co-W ternary phase diagram at WC16 mass $\%$ Co (modified from Ref. 11)).

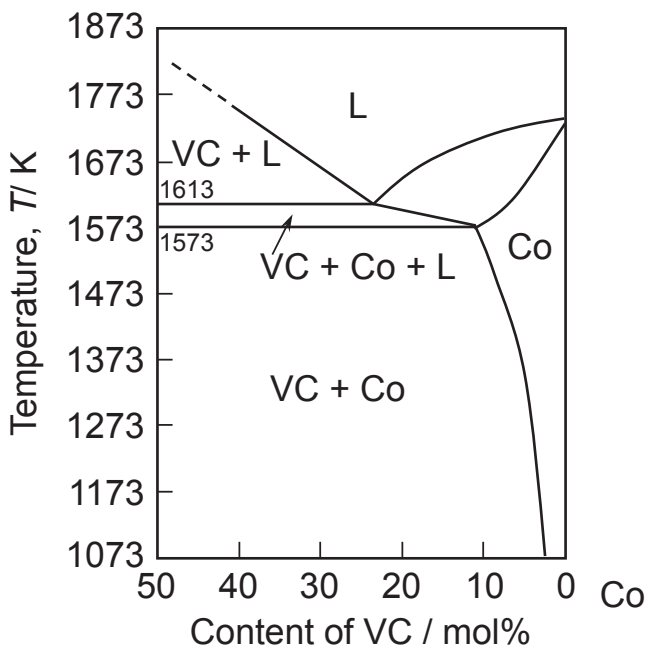

Fig. 10 Pseudobinary VC-Co phase diagram (modified from Ref. 9)).

containing $\mathrm{W}, \mathrm{C}, \mathrm{V}$ and $\mathrm{Cr}$ (i.e., a Co-W-V-Cr-C liquid solution) at the $1593 \mathrm{~K}$ sintering temperature.

We next considered the phase equilibrium between $\mathrm{Co}$ and $\mathrm{VC}$ using the VC-Co pseudobinary phase diagram shown in Fig. 10, excluding the solid WC grains for the sake of simplicity. The diagram was modified here based on Ref. 9). The VC phase most likely becomes a $(\mathrm{V}, \mathrm{W}, \mathrm{Cr}) \mathrm{C}$ phase in a WC-VC-Cr $\mathrm{C}_{2}$-Co cemented carbide, because $\mathrm{W}$ and $\mathrm{Cr}$ can replace a large number of the $\mathrm{V}$ atoms in the $\mathrm{VC}$ crystalline structure. The actual phase equilibrium of the $\mathrm{VC}$ and $\mathrm{Co}$ phase shifts to a lower temperature; i.e., the Co liquidus temperature is reduced by the inclusion of $\mathrm{W}, \mathrm{C}, \mathrm{V}$ and $\mathrm{Cr}$. Based on Hashiya's study, ${ }^{12}$ ) this lower temperature is estimated to be $30-50 \mathrm{~K}$. The solubility limit of $\mathrm{V}$ in the liquid and solid Co phases also decreases as a result of carbide formation, but as the liquid-state-sintering temperature was above the Co liquidus and the $\mathrm{V}: \mathrm{Co}$ atomic composition ratio $(0.7: 26.6)$ of the specimen was still less than the reduced liquid solubility limit, no stable VC phase 
Table 4 Concentrations of elements (at $\%$ ) at $\mathrm{WC}_{\mathrm{B}} / \mathrm{Co}, \mathrm{WC}_{\mathrm{C}} / \mathrm{Co}$ and $\mathrm{WC}_{\mathrm{C}} / \mathrm{WC}_{\mathrm{R}}$ interfaces in the quenched specimen after reheating at $1473 \mathrm{~K}$ for $1.8 \mathrm{ks}$ using a solid-state-sintered specimen.

\begin{tabular}{ccccc}
\hline & $\mathrm{WC}_{\mathrm{B}} / \mathrm{Co}$ & $\mathrm{WC}_{\mathrm{B}} / \mathrm{WC}_{\mathrm{R}}$ & $\mathrm{WC}_{\mathrm{C}} / \mathrm{Co}$ & $\mathrm{WC}_{\mathrm{C}} / \mathrm{WC}_{\mathrm{R}}$ \\
\hline $\mathrm{V}$ & 9 & - & 4 & 2 \\
$\mathrm{Cr}$ & 13 & - & 5 & 11 \\
$\mathrm{Co}$ & 31 & - & 31 & 26 \\
$\mathrm{~W}$ & 47 & - & 60 & 61 \\
\hline
\end{tabular}

was formed during liquid-state sintering. It can therefore be concluded that the $\mathrm{V}$ dissolved completely in the Co liquid phase at the liquid-state-sintering temperature of $1593 \mathrm{~K}$. During subsequent solidification of the Co phase, the VC phase (most likely a $(\mathrm{V}, \mathrm{W}, \mathrm{Cr}) \mathrm{C}_{x}$ phase) should segregate due to the solubility limit of $\mathrm{V}$ in the solid Co phase being less than the amount added. Furthermore, this segregation is likely to preferentially occur at the interface between the WC grains and solid Co phase.

Given the phase equilibrium of $\mathrm{VC}$ and $\mathrm{Co}$ at the solidstate-sintering and semi-sintering temperatures, it is apparent from the pseudobinary $\mathrm{VC}-\mathrm{Co}$ phase diagram in Fig. 10 that the $(\mathrm{V}, \mathrm{W}, \mathrm{Cr}) \mathrm{C}_{x}$ phase at the $\mathrm{WC} / \mathrm{Co}$ and $\mathrm{WC} / \mathrm{Co}$ interfaces is in an equilibrium state at the sintering temperatures of 1473 and $1273 \mathrm{~K}$. To investigate whether the $\mathrm{V}$ and $\mathrm{Cr}$ were segregated at the interfaces before holding or during cooling of the solid-state-sintered specimen, the $\mathrm{V}$ and $\mathrm{Cr}$ concentrations at the interfaces of the specimens reheated to $1473 \mathrm{~K}$ and quenched were also investigated using a solid-statesintered specimen, as shown in Table 4 . The difference in the $\mathrm{V}$ concentration between Tables 2 and 4 (specifically, the effect of quenching from the Co solid state) is very small in comparison with the large difference in this value observed between specimens subjected to quenching and typical cooling from the Co liquid state in previous studies. ${ }^{7,13}$ ) The slight variation in concentration seen between the two different cooling rates for the solid-state-sintered specimen does, however, suggest the presence of a segregation layer at $1473 \mathrm{~K}$. The minimal grain growth during solid-state sintering could be caused by a strong restriction of the dissolution-reprecipitation of the $\mathrm{WC}$ phase due to the existence of the $(\mathrm{V}, \mathrm{W}, \mathrm{Cr}) \mathrm{C}_{x}$ segregation layer formed under increasing temperature. Based on a thermodynamic calculation by Johansson and Wahnström, ${ }^{14)}$ the $(\mathrm{V}, \mathrm{W}, \mathrm{Cr}) \mathrm{C}_{x}$ phase would be expected to dissolve in the Co phase. Moreover, the fact that the WC grain size of the liquid-state-sintered specimen was larger than that of the solid-state-sintered specimen suggests that grain growth during liquid-state sintering is made possible by dissolution of the $(\mathrm{V}, \mathrm{W}, \mathrm{Cr}) \mathrm{C}_{x}$ layer on the WC surface formed under increasing temperatures, in addition to an increase in the sintering temperature.

Johansson and Wahnström reported that an ultrathin $(\mathrm{V}, \mathrm{W}) \mathrm{C}_{x}$ layer with just two $\mathrm{V}$ atoms in thickness may exist stably on the WC(0001) surface at the high temperatures required for liquid-state sintering, under realistic conditions. ${ }^{14)}$ They also determined that this ultrathin layer would hinder $\mathrm{W}$ diffusion into or out of the WC grains. If such an ultrathin layer were to exist stably at the $\mathrm{WC}(0001)$ surface, it is believed that the WC grain growth would then be strongly inhibited compared with the other surface. However, the WC grains in VC-doped WC cemented carbide coarsen with an increase in holding time during liquid-state sintering regardless of their crystal orientation. ${ }^{4)}$ Assuming that an ultrathin layer of 2-V atomic thickness exists on a WC(0001) surface with a triangular prismatic shape of $0.1-\mu \mathrm{m}$ in side-length and $0.05-\mu \mathrm{m}$ in height, in imitation of the specimens used in this study, the $\mathrm{VC}$ atomic ratio necessary for layer formation on the $\mathrm{WC}(0001)$ surface is estimated to be approximately $1.23 \%$ of the $\mathrm{W}$ atomic amount. If the grain growth inhibition mechanism is based on the presence of such an ultrathin layer, then WC grain growth cannot be sufficiently inhibited because the estimated atomic ratio necessary for the ultrathin layer to form is much greater than the actual $\mathrm{V}$ content of the specimen. However, in this study, ultrafine-grained WC-Co cemented carbide with sufficiently inhibited WC grain growth were in fact obtained, as shown in Fig. 1(d). On the other hand, if we assume a submicron-grained WC-Co cemented carbide consisting of WC grains with a triangular prismatic shape of $0.5-\mu \mathrm{m}$ in side-length and $0.25-\mu \mathrm{m}$ in height, WC grain growth can be inhibited using only a small amount of doped $\mathrm{V}$ because an ultrathin layer can form with just a small amount of $\mathrm{V}(0.25 \mathrm{at} \%)$ relative to the $\mathrm{W}$ content. Based on Ref. 15), WC grain growth inhibition due to VC increases with $\mathrm{VC}$ content up to the solubility limit in liquid $\mathrm{Co}$ (in this case, 2.2 at\% V), where a WC-VC-20 mass \%Co is reached. This means that if a stable $(\mathrm{V}, \mathrm{W}) \mathrm{C}_{x}$ layer forms on a $\mathrm{WC}(0001)$ surface during liquid-state sintering, when the $\mathrm{V}$ content in the specimen is below the solubility limit of $\mathrm{V}$ in liquid $\mathrm{Co}$, the grain growth inhibition effect is immune to the effects of any additional VC content. The above two considerations suggest that the $\mathrm{WC}(0001)$ surface in the VCdoped WC-Co cemented carbide is almost never covered by a $(\mathrm{V}, \mathrm{W}) \mathrm{C}_{x}$ layer.

The authors support the conclusion that grain growth during liquid-state sintering is inhibited by the adsorptiondesorption of dopants at steps/kinks on the WC grain surfaces. ${ }^{6,7)}$ The formation of the segregation layer during solid-state sintering suggests that sufficient diffusion force is applied to the $\mathrm{V}$ and $\mathrm{Cr}$ atoms by heating to $1473 \mathrm{~K}$ for $3.6 \mathrm{ks}$ to rearrange the original $\mathrm{WC}, \mathrm{VC}, \mathrm{Cr}_{3} \mathrm{C}_{2}$ and $\mathrm{Co}$ powder configurations in the solid phase. Hence, it is concluded that the $(\mathrm{V}, \mathrm{W}, \mathrm{Cr}) \mathrm{C}_{x}$ segregation layers seen at the $\mathrm{WC} / \mathrm{Co}$ and $\mathrm{WC} / \mathrm{WC}$ interfaces at room temperature are formed during the cooling that follows the liquid-state sintering as a result of the solubility difference between the liquid and solid Co. Thus, the most effective amount of grain-growth inhibitor to use with $\mathrm{WC}$ is a value that lies immediately below its solubility limit in the liquid Co phase at the applied sintering temperature.

\section{Conclusion}

Through HRTEM and EDS analysis of the microstructure and chemical composition at the $\mathrm{WC} / \mathrm{Co}$ and $\mathrm{WC} / \mathrm{WC}$ interfaces in $\mathrm{WC}-0.7 \mathrm{VC}-1.4 \mathrm{Cr}_{3} \mathrm{C}_{2}-10 \mathrm{Co}$ (mass \%) cemented carbides produced by liquid-state-sintering, solid-state-sintering and semi-sintering, and their relation to the phase equilibrium of the WC-Co and VC-Co pseudobinary systems, the following conclusions have been reached: 
(1) Both $\mathrm{V}$ and $\mathrm{Cr}$ segregate at $\mathrm{WC} / \mathrm{Co}$ and $\mathrm{WC} / \mathrm{WC}$ interfaces in liquid-state-sintered, solid-state-sintered and semi-sintered specimens, but their concentrations are independent of the sintering temperature.

(2) In solid-state sintering, the $\mathrm{V}$ and $\mathrm{Cr}$ concentrations at the $\mathrm{WC} / \mathrm{Co}$ and $\mathrm{WC} / \mathrm{WC}$ interfaces are independent of the cooling rate.

(3) A $(\mathrm{V}, \mathrm{W}, \mathrm{Cr}) \mathrm{C}_{x}$ segregation layer is stably formed at sintering temperatures below the solidus temperature of the solid Co phase, but dissolves in the liquid Co phase once the sintering temperature exceeds the Co liquidus temperature.

(4) The $(\mathrm{V}, \mathrm{W}, \mathrm{Cr}) \mathrm{C}_{x}$ segregation layer observed in the specimen at room temperature is mainly formed during solidification of $\mathrm{Co}$, which occurs as a result of the difference in the solubility limit between liquid and solid Co.

(5) The WC grain growth inhibition mechanism during liquid-state sintering is based on the dopant adsorption/ desorption process at steps/kinks, which hinders W precipitation.

\section{Acknowledgments}

The authors would like to express their considerable appreciation to Prof. N. Masahashi (Institute for Materials Research, Tohoku University), who provided carefully considered feedback and valuable comments during the course of this research.

\section{REFERENCES}

1) K. Hayashi, Y. Fuke and H. Suzuki: J. Jpn. Soc. Powder Powder Metall. 19 (1972) 67-71 [in Japanese].

2) H. Tulhoff: Mod. Develop. Powder Metall. 14 (1980) 269-279.

3) A. Bock: Powder Metall. Int. 24 (1992) 20-26.

4) S. Lay, J. Thibault and S. Hamar-Thibault: Philos. Mag. 83 (2003) 1175-1190.

5) I. Sugiyama, Y. Mizukami, T. Taniuchi, K. Okada, F. Shirase, T. Tanase, Y. Ikuhara and T. Yamamoto: Int. J. Refract. Met. Hard Mater. 30 (2012) 185-187.

6) K. Hayashi: Handbook of Ultrafine Powder, (Fuji Technosystem, Tokyo, 1990) pp. 509-515 [in Japanese].

7) M. Kawakami, O. Terada and K. Hayashi: J. Powder Powder Metall. 51 (2004) 576-585.

8) M. Kawakami, O. Terada and K. Hayashi: J. Powder Powder Metall. 52 (2005) 166-171.

9) G. P. Dmitrieva, Z. B. Krasnokutskaya, N. N. Belyavina and A. K. Shurin: Sov. Powder Metall. Met. Ceram. 28 (1989) 233-238.

10) S. Lay, S. Hamar-Thibault and A. Lackner: Int. J. Refract. Met. Hard Mater. 20 (2002) 61-69.

11) J. Gurland: Trans. Metall. Soc. AIME 200 (1954) 285-290.

12) M. Hashiya, Y. Kubo, C. Gieri and W. D. Schubert: Proc. the 17th Int. Plansee Seminar Vol. 2, (Reutte, Plansee 2009) HM55, pp. 1-17.

13) M. Kawakami, O. Terada and K. Hayashi: Proc. Int. Plansee Seminar Vol. 2, (Reutte, Plansee 2005) pp. 653-667.

14) S. A. E. Johansson and G. Wahnström: Philos. Mag. 90 (2010) 599609.

15) K. Hayashi, Y. Fuke and H. Suzuki: J. Powder Powder Metall. 19 (1972) 67-71 [in Japanese]. 